\title{
DYSPEPSIA MANAGEMENT
}

\section{Natural history of dyspepsia}

\section{Agréus}

Gut 2002;50(Suppl IV):iv2-iv9

Many individuals in the Western world suffer from heartburn, acid regurgitation, abdominal pain, or bowel habit disturbances. The reported prevalence of dyspepsia is approximately $25 \%$ with similar values for gastro-oesophageal reflux disease. While prevalence rates are stable over time, substantial changes occur in the main symptom profiles of sufferers. The economic costs of dyspepsia are considerable.

\section{SUMMARY}

A new definition of dyspepsia has been proposed: pain or discomfort centred in the upper abdomen. Here, discomfort refers to a subjective negative feeling but one that the patient does not interpret as pain. Duration is not specified. Concomitant predominant reflux symptoms are separated out as gastro-oesophageal reflux disease (GORD). Irritable bowel syndrome (IBS) pain is also an exclusion criterion if epigastric pain is related to bowel habit disturbances. If not, IBS and dyspepsia can present concomitantly. Reported prevalences of dyspepsia vary considerably, with the average reported value being approximately $25 \%$. Similar values are reported for GORD. The simultaneous occurrence of reflux, dyspeptic, and IBS symptoms is common. Prevalence rates are stable over time but substantial changes occur in the main symptom profiles of sufferers. Those reporting predominant reflux have fluctuating symptom intensity but rarely change their main symptom profile to dyspepsia or IBS. The two latter disorders also change in intensity over time but sufferers often change their main symptom profile between the two diagnoses, although not to predominant reflux. Psychosocial factors such as neuroticism, mood disorders, and quality of life have been found to contribute to the morbidity associated with dyspepsia. The economic costs of dyspepsia are hard to compare between countries because of differences in sickness benefits and drug prescription rules and subsidies. In Sweden, the overall cost seems to have decreased substantially over the past decade, mostly because of a decrease in the cost of short term sick leave arising from impaired sickness benefits, while the cost of drugs has increased.

\section{INTRODUCTION}

Many individuals in the Western world are troubled by heartburn, acid regurgitation, abdominal pain, or bowel habit disturbances; up to one in two subjects in cross sectional population based studies report such symptoms. ${ }^{1-4}$ The reported prevalence of symptomatic GORD has ranged, on average, from $15 \%$ to $25 \%,{ }^{5-9}$ while for dyspepsia the reported prevalence range in populations is $15-40 \% .^{1{ }^{3}{ }^{10-12}}$ One reason for the wide ranges reported is that there have been no overall agreed definitions of the disorders.

\section{DEFINITION OF DYSPEPSIA}

For a long time, dyspepsia had no generally agreed definition, ${ }^{13}$ causing difficulties for both clinicians and researchers. Then, in the late 1980s, an international working group, assembled in Chicago, recommended that dyspepsia be defined broadly as any epigastric or retrosternal symptom of supposed gastrointestinal origin lasting for more than four weeks. ${ }^{14}$ It was also suggested that symptoms be pooled into four subgroups to reflect their most likely underlying pathophysiology, and therefore guide clinicians in their choice of therapy. The subgroups were labelled refluxlike, ulcer-like, dysmotility-like, and unspecified (non-specific) dyspepsia. The set of symptoms for each of these subgroups is presented in table 1. With this definition of dyspepsia, all individuals reporting symptoms of GORD were included, and concomitant IBS was not considered an exclusion criterion.

In 1991, the Rome working party proposed that dyspeptic patients with predominant reflux symptoms (heartburn and acid regurgitation) should be considered as having GORD until proved otherwise ${ }^{15}$ because the majority of these patients will have an organic cause for their symptoms (that is, macroscopic or histological oesophagitis). ${ }^{16}{ }^{17}$ In addition, those presenting with concomitant IBS symptoms should be diagnosed as having IBS and not dyspepsia. Dyspepsia was defined more clearly and simply as pain or discomfort centred in the upper abdomen. Chronic dyspepsia was defined as dyspeptic symptoms present for at least $25 \%$ of the time for at least one month. Functional (non-ulcer) dyspepsia was defined as chronic dyspepsia in the absence of a definite structural disease. Only ulcer-like, dysmotility-like, and unspecified dyspepsia were considered as subgroups.

The 1991 Rome definition is now widely accepted although still under debate. The terms pain and discomfort may be interpreted differently in different countries and cultures, ${ }^{18}{ }^{19}$ and the definition may not cover all of the possible linguistic aspects of dyspepsia. ${ }^{2}$ A new working team has therefore proposed an updated definition, referred to as the Rome II definition. ${ }^{20}$ This

Abbreviations: BMI, body mass index; DDD, defined daily doses; GORD, gastro-oesophageal reflux disease; IBS, irritable bowel syndrome; OR, odds ratio. 
Table 1 Dyspepsia subgroups and symptom profiles according to former definitions $^{14}$

- Reflux-like dyspepsia

Heartburn

Acid regurgitation

- Ulcer-like dyspepsia

Three or more of the following symptoms, but upper abdominal pain must be predominant

Epigastric pain

Pain relieved by food

Pain relieved by antacids or acid reducing drugs

Pain occurring before meals or when hungry

Pain that at times wakes the patient from sleep

Periodic pain with remission and relapses

- Dysmotility-like dyspepsia

Pain is not a dominant symptom but upper abdominal discomfort should be present, and characterised by

three or more of the following

Early satiety

Postprandial fullness

Nausea

Retching and/or vomiting that is recurrent

Bloating in the upper abdomen not accompanied by visible distension

Upper abdominal discomfort often aggravated by food

- Unspecified (non-specific) dyspepsia

Dyspeptic symptoms that cannot be classified into the above three symptom profiles

Table 2 Dyspepsia subgroups based on the predominant or most bothersome symptoms, according to the Rome II working team ${ }^{20}$

- Ulcer-like dyspepsia

Pain centred in the upper abdomen is the predominant (most bothersome) symptom

- Dysmotility-like dyspepsia

An unpleasant or troublesome non-painful sensation (discomfort) centred in the upper abdomen is the predominant symptom; this sensation may be characterised by or associated with upper abdominal

fullness, early satiety, bloating, belching, or nausea

- Unspecified dyspepsia

Cannot be classified as above

still defines dyspepsia as pain or discomfort centred in the upper abdomen but further clarification has been added. "Centred" refers to symptoms mainly in or around the midline. Whether or not discomfort represents part of the spectrum of pain is discussed, and the term discomfort is taken to refer to a subjective negative feeling but one that the patient does not interpret as pain (in all languages and cultures) and which, if fully assessed, can include a number of specific symptoms. Discomfort may be characterised by, or associated with, upper abdominal fullness, early satiety, bloating, belching, or nausea. These symptoms are typically accompanied by a component of upper abdominal distress. Duration is not specified as part of the definition. Concomitant predominant reflux symptoms are separated out as GORD and not called dyspepsia. IBS pain is also an exclusion criterion if the epigastric pain is related to bowel habit disturbances. If not, IBS and dyspepsia can present concomitantly.

The dyspepsia subgroups shown in table 1 have been questioned because there does not appear to be a clinically useful connection between the symptom subgroups and pathophysiology. ${ }^{21}$ The prevalence of peptic ulcers is approximately the same in all symptom clusters, and dysmotility and unspecified hypersensitivity do not differ in a clinically useful way. Hence the groups do not guide the clinician, as originally intended, when choosing between prokinetic and acid reducing drugs for patients with uninvestigated dyspepsia. The Rome II working team emphasises this and proposes that "the predominant or most bothersome symptoms" should be identified as a working hypothesis for future research to test. The dyspepsia subgroups based on this concept are shown in table 2 .

\section{PREVALENCE OF DYSPEPSIA AND GORD}

\section{Dyspepsia}

The reported prevalence of dyspepsia varies considerably, to some extent depending on the various definitions used and also on the period of time patients are under surveillance. Values of between $7 \%^{22}$ and $63 \%$ have been reported, with a mean of approximately $25 \%$. The overall findings from studies of different populations are given below, in chronological order.

In England in 1951, Doll and Jones reported dyspeptic symptoms in $32 \%$ of males and $30 \%$ of females during the five years preceding their investigation, with worse symptoms occurring in males. ${ }^{23}$ Weir and Backett in 1968 reported a 23\% prevalence rate for dyspepsia over a three month period in Scottish males, with $29 \%$ having had dyspepsia at some point in their life. ${ }^{24}$ In this study, the proportion of more harmless symptoms decreased with age. In a Swedish investigation published by Johansson in 1970, 21\% of individuals had suffered abdominal pain over the previous year and, of these, one in four reported severe pain; the prevalence was about the same in both sexes, decreasing with age mainly among those reporting mild symptoms. ${ }^{25}$ Banke in 1975 found that $26 \%$ of the Danish population reported dyspepsia, with a maximum value of 34\% in younger (25-35 years) males and 32\% in older (35-65 years) females. ${ }^{26}$

In the 1980s, in a Swedish survey, Tibblin et al reported a decrease with age in almost all of the abdominal symptoms investigated, the decrease being most marked in females; the prevalence of dyspepsia over three months was about $26 \%$ in 50 year olds but abdominal pain was reported by $39 \%$ of younger females. ${ }^{27}{ }^{28}$ In 1982, Hollnagel et al reported that $25 \%$ of the 40 year old Danish population had suffered epigastric 


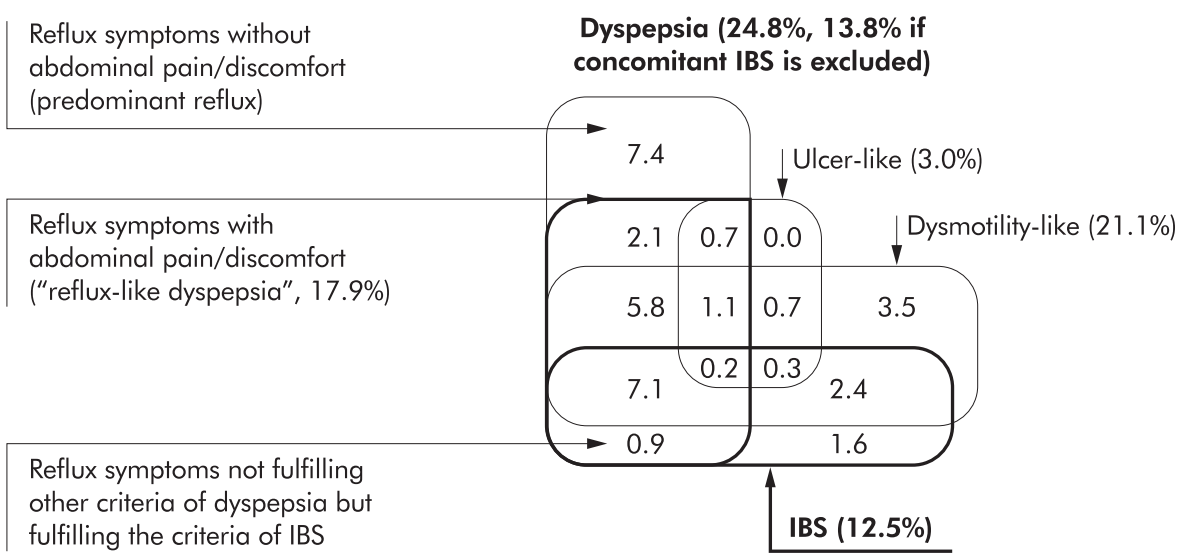

Figure 1 Percentage of responders in a population based study reporting dyspepsia, dyspepsia subgroups, and irritable bowel syndrome (IBS)..$^{2}$ The prevalence of "overall" dyspepsia includes reflux symptoms and is given with and without concomitant IBS symptoms.

pain during the year preceding the survey, and that $31 \%$ had experienced such pain at some point in their life. ${ }^{10}$ In a Norwegian total population survey in 1988, Johnsen et al found the lifetime prevalence of non-ulcer dyspepsia to be $23 \%$ among males and $18 \%$ among females-the prevalence increased significantly with age in both sexes, as did reflux symptoms. ${ }^{11}$ In a Peruvian urban population studied by Barrós and Pamo in $1989,54 \%$ were found to have dyspepsia. ${ }^{29}$

In two studies published by Jones and Lydeard in 1989 and 1990, the six month prevalence of dyspeptic symptoms was $38 \%$ and $41 \%$; there was no difference between males and females except for a decrease with age that was significant only in males, and the lifetime prevalence was $63 \% .{ }^{130}$ Also in 1990, Bernersen et al reported that $27 \%$ of their Norwegian study population had suffered from epigastric pain and/or heartburn at some point. ${ }^{31}$ In a random community based survey in rural northeastern Nigeria in 1991, Holcombe et al reported a $26 \%$ prevalence of dyspepsia over six months which increased with age. ${ }^{32}$ However, in a previous study from the same country, the prevalence was $45 \%$ for the same time span. ${ }^{33}$ Schlemper et al in 1993 found a prevalence of non-ulcer dyspepsia of $13 \%$ in both the Netherlands and Japan in working populations ${ }^{34}$; the prevalence was twice as high among females in both countries. In 1997, in a preliminary report from Hong Kong, Hu et al found a prevalence of $19 \%$ in a Chinese population. ${ }^{35}$ Holtmann et al reported a $21 \%$ prevalence of dyspepsia over one year in a German randomly selected population. ${ }^{36}$

In southern Europe the reports are sparse. Cupella et al reported that $61 \%$ of a small sample of workers $(n=102)$ in Italy had dyspepsia ${ }^{37}$ although it is doubtful whether this

Table 3 The three month incidence (number per 100) in a Swedish population based study of predominant reflux symptoms (no concomitant abdominal pain; "reflux"), dyspepsia (only reflux and irritable bowel syndrome (IBS) excluded) and IBS ${ }^{12}$

\begin{tabular}{lllll}
\hline \multicolumn{5}{l}{ Incidence (\%)* } \\
\cline { 2 - 5 } & $\%$ & $95 \% \mathrm{Cl}$ & $\%$ & $95 \% \mathrm{Cl}$ \\
\hline Reflux & $0.05 \dagger$ & $0.00-0.25$ & $0.75 \dagger$ & $0.20-1.30$ \\
Dyspepsia & 0.8 & $0.0-1.6$ & 1.0 & $0.4-1.6$ \\
IBS & 0.2 & $0.0-0.6$ & 0.5 & $0.0-1.0$ \\
\hline
\end{tabular}

*Denotes newly occurring disease among those who were previously symptom free and those who had other symptoms/symptom clusters previously (but not the cluster under consideration)

†Based on one year occurrence.

$\mathrm{Cl}$, confidence interval. result can be extrapolated to the general population. In France, for example, Bommelaer et al reported abdominal pain in $14 \%$ of a random population ${ }^{38}$; however, $14 \%$ seems low compared with other studies on overall abdominal pain-in a Swedish study by Agréus et al, the three month prevalence of having any troublesome abdominal pain was $36 \%{ }^{12}$ and in a study by Welch and Pomare in New Zealand, values were 26\% for males and $32 \%$ for females. ${ }^{39}$

In Olmsted County, Minnesota, USA, Talley et al reported a one year overall prevalence of dyspepsia of $26 \%$, with $16 \%$ of these having ulcer-like dyspepsia. ${ }^{3}$ In Australia, a prevalence of dyspepsia of $12 \%$ has been reported by Talley et al for a 12 month period. ${ }^{4}$ In the Swedish study cited above, the overall prevalence of dyspepsia in the unselected population was $32.2 \%$ for a three month period. ${ }^{12}$ If those patients with only reflux symptoms ("predominant reflux") were excluded, $24.8 \%$ were defined as having dyspepsia, and $13.9 \%$ if those with concomitant bowel habit disturbances ( that is, IBS) were also excluded (fig l).

\section{GORD}

As with dyspepsia, the definitions of GORD used in different investigations are divergent. However, when attempting to identify individuals suffering from heartburn or acid regurgitation, approximately $25 \%$ of the population seems to report reflux symptoms, and about one third of these "predominant reflux symptoms". Again, the main conclusions from such studies are given below in chronological order.

In a non-randomly selected US population, Nebel et al in 1976 reported prevalences of 7\% for daily heartburn and 36\% for monthly heartburn among responders, with no significant trend for age. ${ }^{5}$ Kjellén and Tibbling in 1981 found acid regurgitation or heartburn in $16 \%$, dysphagia in $15 \%$, globus sensations in $12 \%$, and "chest oppression sensation" in $23 \%$ of a

Table 4 Symptom overlap in dyspepsia and irritable bowel syndrome (IBS) in patient and population based studies

Percentage of individuals with IBS reporting concomitant dyspepsia

Dotevall et $a^{45}$

Talley et $a^{\beta}$

Jones and Lydeard ${ }^{46}$

Agréus et $a l^{12}$

Percentage of individuals with dyspepsia reporting concomitant IBS

Hollnagel et $a^{10}$

Talley and Piper ${ }^{47}$

Sielaff ${ }^{48}$
$87 \%$

$29 \%$ *

$90 \%$ *

$80 \%$ *

$46 \%$ *

$23 \%$

$47 \%$
*Population based studies 


\begin{tabular}{|c|c|c|c|}
\hline Reference and diagnosis & Time period & Survey follow up & $\begin{array}{l}\text { Percentage at } \\
\text { follow up still } \\
\text { reporting } \\
\text { symptoms }\end{array}$ \\
\hline \multicolumn{4}{|l|}{ Weir and Backett ${ }^{24}$} \\
\hline Dyspepsia & 3 months & 3 years & 65 \\
\hline \multicolumn{4}{|l|}{ Jones and Lydeard ${ }^{42}$} \\
\hline Dyspepsia & 6 months & 2 years & 74 \\
\hline \multicolumn{4}{|l|}{ Talley et $a^{43}$} \\
\hline Abdominal pain & 1 year & $12-20$ months & 82 \\
\hline Dyspepsia & & & 86 \\
\hline IBS (Mannings criteria) & & & 86 \\
\hline IBS (Rome criteria) & & & 93 \\
\hline \multicolumn{4}{|l|}{ Agréus et $a l^{12}$} \\
\hline Predominant reflux symptoms & 3 months & 1 year & 41 \\
\hline Dyspepsia & & & 43 \\
\hline IBS & & & 50 \\
\hline Symptom free & & & 80 \\
\hline \multicolumn{4}{|l|}{ Kay and Jørgensen ${ }^{50}$} \\
\hline Dyspepsia & 1 year & 5 years & 75 \\
\hline \multicolumn{4}{|l|}{ Locke et $a^{51}$} \\
\hline Dyspepsia & 1 year & 4 years & 51 \\
\hline IBS & & & 25 \\
\hline \multicolumn{4}{|l|}{ Agréus et $a^{52}$} \\
\hline Predominant reflux symptoms & 3 months & 7 years & 29 \\
\hline Dyspepsia & & & 30 \\
\hline IBS & & & 55 \\
\hline Symptom free & & & 65 \\
\hline
\end{tabular}

IBS, irritable bowel syndrome.

population of 55 year old males in Sweden. ${ }^{6}$ Thompson and Heaton in 1982 found that heartburn was experienced weekly by $10 \%$, monthly by $21.3 \%$, and at some point during the previous year by $34 \%$ of responders in a UK study; they found no significant difference by sex but there were more complaints among the elderly (aged 60 years and older). ${ }^{7}$ In a population based study in 1990, also in the UK, Jones et al found that 31\% had experienced heartburn in the preceding six months, and that $56 \%$ of those with upper abdominal complaints reported concurrent heartburn. ${ }^{1}$ In another Swedish study in 1991, Ruth et al reported symptoms suggestive of GORD in $25 \%$ of a randomly sampled population; $21 \%$ reported heartburn, $20 \%$ acid regurgitation, and $12 \%$ non-cardiac chest pain, and they found no difference with age or sex. ${ }^{8}$ Talley et al in 1992 found that $24 \%$ of a US study population reported having suffered heartburn at least once a month during the preceding year, and that $11 \%$ reported acid regurgitation; they also found no significant differences with age or sex. ${ }^{3}$ Räihä et al, also in 1992, reported the prevalence of daily reflux symptoms among Finnish females over 65 years of age to be $15 \%$, and monthly symptoms were reported by $66 \%$ of this study population; the corresponding values in males over 65 years of age were $8 \%$ and $55 \%$, respectively. ${ }^{40}$ In a paper published by Agréus et al in 1995, 25.3\% of a Swedish population reported reflux symptoms; one third $(7.4 \%$ of the population) reported no concomitant abdominal symptoms and were therefore considered to have predominant reflux symptoms (that is, GORD) (fig 1)..$^{12}$ In a paper published in 1997 by Locke et al, $19.8 \%$ of a US study population reported acid regurgitation and/or heartburn weekly, and $58.9 \%$ at some point during the previous year.' In Australia, a prevalence of gastro-oesophageal symptoms of $17 \%$ over a 12 month period has been reported by Talley and colleagues. ${ }^{4}$

\section{INCIDENCE OF DYSPEPSIA AND GORD}

There are only a handful of studies on the incidence (new cases) and onset (new symptoms or old symptoms that recur) of dyspepsia and reflux symptoms. Data are hard to compare because of confusion in the terminology. In Scotland, Weir and Backett reported an annual incidence of dyspepsia of $1.6 \%^{24}$ while in Denmark, Kay and Jørgensen found an annual incidence of dyspepsia of just under $25 \% .{ }^{41}$ In an English study, Jones and Lydeard reported an annual incidence (the participants had never experienced the symptom before) of $11.5 \%$ for dyspepsia, ${ }^{42}$ while in the USA, Talley et al reported annual onset rates (the subjects were symptomless at the first but not the second survey although they could have had symptoms in the distant past) of $5.6 \%$ for dyspepsia and $6.6 \%$ for IBS ${ }^{43}$ They also reported annual onset rates of $2.0 \%$ for heartburn several times a week or daily, $5.0 \%$ for heartburn once a month or more, and $3.9 \%$ for acid regurgitation once a month or more. In Sweden, Lööf et al calculated the annual incidence of reflux oesophagitis, using upper gastrointestinal endoscopy, to be 120 per 100000 inhabitants in a primary healthcare population ${ }^{44}$ However, this study probably underestimated the incidence of gastro-oesophageal reflux symptoms as it was a patient based study on oesophagitis. In another Swedish population based study, the reported values were lower than in most other studies, probably because the methodology excluded those with prior, now recurrent, symptoms. ${ }^{12}$ Table 3 shows the three month incidence of predominant reflux symptoms, dyspepsia, and IBS in this population.

\section{SYMPTOMS}

\section{Symptom overlap}

The symptoms of dyspepsia, often including reflux symptoms, and IBS overlap to a considerable extent, as shown in table 4. The symptom overlap and proportion of those with reflux symptoms reporting and not reporting dyspepsia (the latter defined as "predominant reflux symptoms") in a Swedish population based study are shown in fig $1 .{ }^{12}$

\section{Symptom change over time}

Although often chronic, the pain or discomfort suffered with dyspepsia is frequently intermittent, even during a period 


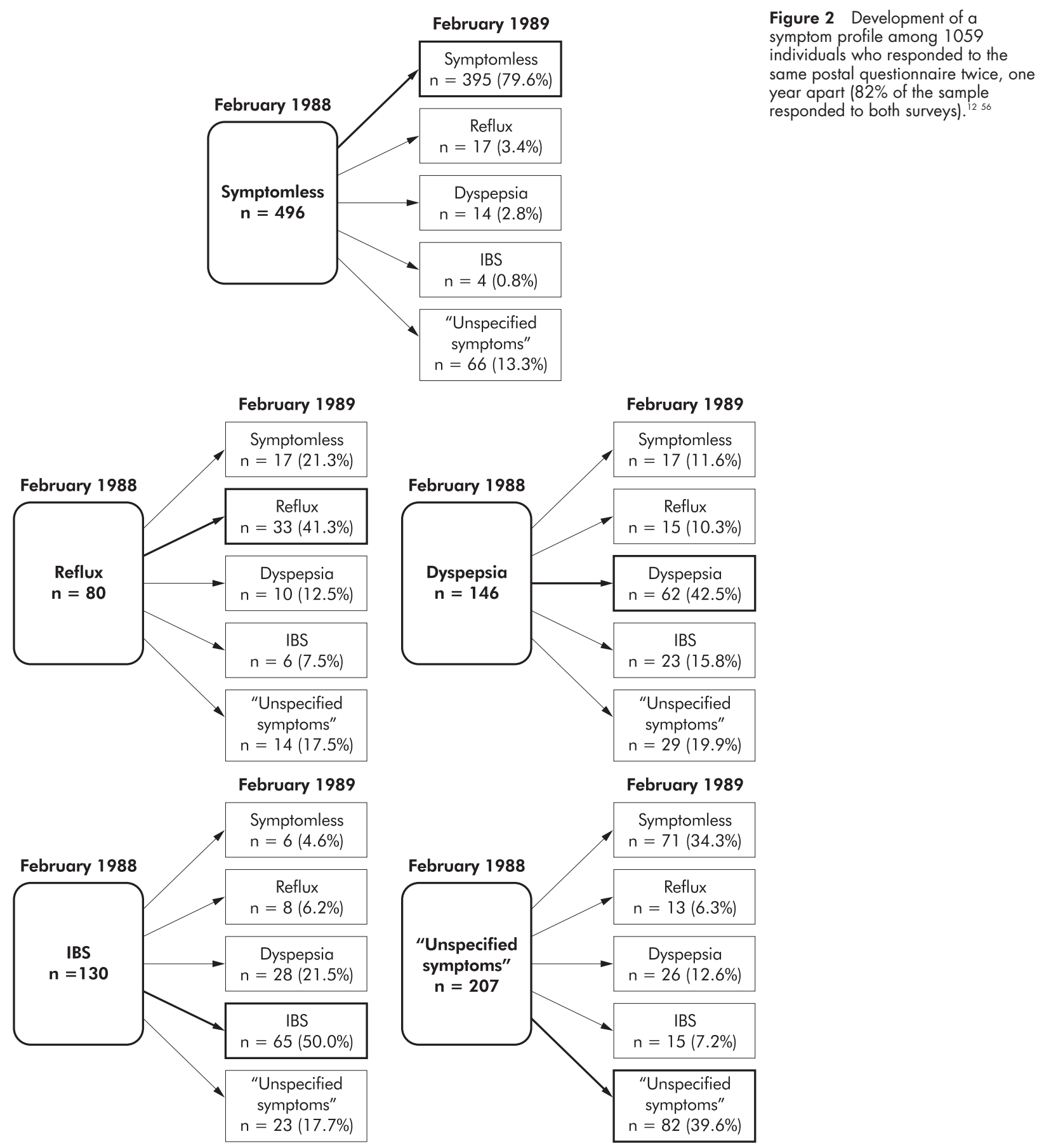

with marked symptoms. ${ }^{49}$ Most studies on symptom turnover however examined the changes over longer periods. Studies that have been undertaken on symptom change over time are shown in table 5. Talley et al, for example, found that about $86 \%$ of individuals with frequent symptoms had the same symptom profile 12-20 months later. ${ }^{43}$ However, Palmer found that spontaneous recovery was three times more common than impairment among untreated GORD patients. ${ }^{53}$ Unfortunately, the results of a study by Schindlbeck et al were less encouraging- $68 \%$ of patients $(n=105)$ with GORD had the same or worse symptoms after three years. ${ }^{54}$ Furthermore, Ruth found that the majority of patients with GORD still reported symptoms in a 10 year follow up. ${ }^{55}$

The results of a one year study of symptom turnover in a Swedish population $(n=1059)$ are shown in fig $2 .{ }^{12}{ }^{56}$ At least half of the individuals had changed their main symptom pro- file over one year. However, when the same population was studied again after seven years (843 individuals (79.1\%) of the original population responded to the questionnaire), a somewhat different pattern of symptom turnover was recorded. ${ }^{52}$ Those patients who were symptom free remained largely symptom free. Those with predominant reflux symptoms kept reporting reflux symptoms to a varying degree but they seldom changed their main symptom profile to dyspepsia or IBS. In contrast, the flux between the diagnoses of dyspepsia and IBS was substantial. There would therefore appear to be two distinct populations of patients reporting symptoms among those with functional gastrointestinal disorders: those with symptoms of dyspepsia or IBS, with common variation in between, and those with predominant reflux symptoms. This would also suggest different pathophysiologies for the symptoms of these two populations. 


\section{PREDICTORS OF SYMPTOMS}

When studying factors associated with the onset of a multifaceted disorder such as dyspepsia, methodological issues are crucial. Non-relevant covariation must be controlled using multivariate analysis.

\section{Sociodemographic and environmental factors}

In the Swedish study by Agréus et al, risk factors for developing functional gastrointestinal symptoms were studied among symptomatic individuals who had been symptom free one year previously. ${ }^{12}$ In a univariate analysis, family size, educational level, and being listed sick during the previous three months were positively associated and age was negatively associated with the risk of developing symptoms, while sex, previous abdominal surgery, hormone treatment (in females), and the use of intrauterine devices were unrelated to the risk. When the univariate significant factors (including age and sex) were included in a multivariate model, educational level (odds ratio (OR; both sexes) 1.2; 95\% confidence interval (CI) 1.0-1.5) and being listed sick during the previous three months (OR (both sexes) 2.9; 95\% CI 1.1-7.7) remained weak predictive factors. However, this study can be criticised because some of the potential risk factors were not assessed and could not therefore be introduced into the model.

In Denmark, Kay and Jørgensen studied the influence of sex, age, social class, psychiatric vulnerability, experience of problems, body mass index (BMI), smoking, alcohol intake, coffee and tea intake, and intake of hormones (among females), and found that after multivariate analysis only psychiatric vulnerability significantly increased the risk of dyspepsia, while smoking and a high BMI decreased the risk. ${ }^{41}$ Elta et al found that coffee increased the risk of developing functional dyspepsia ${ }^{57}$ while Talley et al found no such association. ${ }^{58}$ Instead, they found a significant association between the intake of certain analgesics (acetaminophen) and dyspepsia. Holtmann et al, in a multivariate analysis, also found that analgesics increased the risk, while the intake of alcohol decreased the risk of developing dyspepsia. ${ }^{36}$ However, Jones and Lydeard ${ }^{30}$ and Talley and colleagues ${ }^{59}$ found no association between sociodemographic and environmental factors. Thus, in summary, there are no unequivocal trends for such factors in the literature.

\section{Psychosocial factors}

Functional dyspepsia has been found to be associated with psychopathology, including neuroticism and mood disorders, among outpatients, ${ }^{60}{ }^{61}$ and this may be more pronounced than in peptic ulcer disease. ${ }^{62}$ In addition, somatisation, fear of malignancy, a negative assessment of health, depression, and poor social networks and coping strategies have been found to contribute to the morbidity associated with GORD and dyspepsia. ${ }^{63}$ In particular, the fear of a serious or fatal disease and the occurrence of such diseases among relatives and friends have been found to be associated with healthcare seeking behaviour in patients with dyspepsia. ${ }^{64}$ Other studies have focused on the severity and frequency of perceived symptoms as being important factors. ${ }^{365}$ Population based studies have shown that patients with IBS who consult their doctors have greater psychological morbidity than those who do not consult ${ }^{66}$ but this has not been convincingly shown for individuals suffering from dyspepsia.

\section{COSTS OF DYSPEPSIA AND GORD}

The 1997 annual cost of dyspepsia and GORD in Sweden has been calculated, in a preliminary report, to be US\$360 million or US $\$ 40$ per person (table 6) (Agréus L. Economic impact of dyspepsia. Presented at the satellite meeting New Approaches to the Management of Dyspeptic Symptoms, held at the XXXth Nordic Meeting of Gastroenterology, Uleåborg, Finland, 1998).
Table 6 Costs of dyspepsia and gastro-oesophageal reflux disease in Sweden in 1997 (Agréus L. Economic impact of dyspepsia. Presented at the satellite meeting New Approaches to the Management of Dyspeptic Symptoms, held at the XXXth Nordic Meeting of Gastroenterology, Uleåborg, Finland, 1998)

\begin{tabular}{lcc}
\hline & $\begin{array}{c}\text { US\$ } \\
\text { (millions) }\end{array}$ & $\begin{array}{l}\text { Percentage } \\
\text { of cost }\end{array}$ \\
\hline Visits to primary care physicians & 44 & 12 \\
Visits to specialists & 6 & 2 \\
Inpatient care & 4 & 1 \\
Investigations (upper gastrointestinal & 30 & 8 \\
endoscopies) & 170 & 47 \\
Drugs & 84 & 23 \\
Sick leave & 13 & 4 \\
Sickness pension & 9 & 3 \\
Time off work, etc. & 360 & \\
Total & & \\
\hline
\end{tabular}

Almost half (47\%) of the cost was for drugs, and two thirds of these costs were for proton pump inhibitors (table 7). ${ }^{67}$ The comparative cost from 1991 for the same country was US $\$ 825$ million (after adjusting for the consumer price index and currency rate changes), with $90 \%$ of the cost being for short term sick leave, and just $2 \%$ for drugs. ${ }^{68}$ It is obvious that impairment in sickness benefits in Sweden has substantially reduced the costs to society-the qualifying period before benefit has been reduced from none in 1991 to one day in 1997, and the proportion of income loss compensation for sick leave has been reduced from $90-100 \%$ in 1990 to approximately $75-85 \%$ in 1997. On the other hand, most of the increase in drug costs is caused by an increase in the use of proton pump inhibitors. Whereas the use of $\mathrm{H}_{2}$ receptor antagonists has increased slightly from 6.6 to 6.8 defined daily doses (DDD)/1000 inhabitants between 1991 and 1997, the use of proton pump inhibitors has increased from 2.4 to 14.9 DDD/1000 inhabitants. ${ }^{67}$ Hopefully, this reflects a rational use of the drugs for GORD and for the eradication of Helicobacter pylori in patients with peptic ulcer disease, and not an overuse of empirical treatment by chance in functional dyspepsia.

In another Swedish study on a population based sample from 1988, 8.5\% of individuals with dyspepsia and 6.9\% of those with GORD were listed as sick (for any reason) in the previous three months ${ }^{65}$ compared with $1.8 \%$ of those free from functional abdominal disorders. Approximately 5\% of those with dyspepsia or reflux had consulted a doctor in the previous three months, and $50 \%$ of those in the oldest age group (that is, "life prevalence") had ever done so concerning dyspepsia or GORD. The overall drug consumption was substantial-approximately one in four had used drugs for gastrointestinal disorders during the previous three months and another $7 \%$ had used drugs for other disorders. For the

Table 7 Drug sales (proportion of the cost per group) for dyspepsia, gastro-oesophageal reflux disease, and "gastritis" in Sweden in 1996; total cost US\$170 million ${ }^{67}$

\begin{tabular}{lc}
\hline & $\begin{array}{l}\text { Percentage } \\
\text { of cost }\end{array}$ \\
\hline Antacids/alginates & 6 \\
$\mathrm{H}_{2}$ receptor antagonists & 21 \\
Proton pump inhibitors & 67 \\
Prokinetics & 6 \\
\hline
\end{tabular}


third with the worst rated symptoms, approximately 35\% had used a gastrointestinal drug and $10 \%$ other drugs during the same time span.

A US study found the mean costs to a health maintenance organisation of "gastritis", reflux disease, and peptic ulcer disease to be US $\$ 25$ per person, or about one fifth of the costs of diabetes mellitus ${ }^{69}$ The costs do not include the costs of sick leave or a sickness pension. The proportions were $22.6 \%$ for dyspepsia, $36.8 \%$ for peptic ulcer disease, and $40.6 \%$ for GORD. For those with dyspepsia, $6 \%$ of the costs were for inpatient care, $80 \%$ for outpatient care, and $14 \%$ for drugs. Values for peptic ulcer disease were $71 \%, 23 \%$, and $6 \%$, respectively, and for GORD $28 \%, 57 \%$, and $15 \%$. These values show a completely different pattern of cost distribution compared with the Swedish studies ${ }^{68}$ (Agréus L. Economic impact of dyspepsia. Presented at the satellite meeting New Approaches to the Management of Dyspeptic Symptoms, held at the XXXth Nordic Meeting of Gastroenterology, Uleåborg, Finland, 1998), indicating how important it is to consider the impact of different social and healthcare insurance systems, as well as other cultural influences when comparing costs for diseases.

\section{CONCLUSION}

Dyspepsia is a common, long term, fluctuating, symptom shifting, and expensive disorder.

Conflict of interest: This symposium was sponsored by AstraZeneca, makers of omeprazole. The author of this paper has received sponsorship for travel and an honorarium from AstraZeneca.

\section{REFERENCES}

1 Jones $\mathbf{R}$, Lydeard SE, Hobbs FD, et al. Dyspepsia in England and Scotland. Gut 1990;31:401-5.

2 Agréus L, Svärdsudd K, Nyrén O, et al. The epidemiology of abdominal symptoms: prevalence and demographic characteristics in a Swedish adult population. A report from the Abdominal Symptom Study. Scand J Gastroenterol 1994:29:102-9.

3 Talley NJ, Zinsmeister AR, Schleck CD, et al. Dyspepsia and dyspepsia subgroups: a population-based study. Gastroenterology 1992;102:1259-68

4 Talley $\mathbf{N}$, Boyce $\mathrm{P}$, Jones $\mathrm{M}$. Identification of upper and lower gastrointestinal symptom groupings in an urban population. Gut 1998;42:690-5.

5 Nebel OT, Fornes MF, Castell DO. Symptomatic gastroesophageal reflux: incidence and precipitating factors. Am J Dig Dis 1976;21:953-6

6 Kjellén G, Tibbling L. Manometric oesophageal function, acid perfusion test and symptomatology in a 55-year-old general population. Clin Physiol 1981;1:405-15.

7 Thompson WG, Heaton KW. Heartburn and globus in apparently healthy people. Can Med Assoc J 1982;126:46-8.

8 Ruth M, Månsson I, Sandberg N. The prevalence of symptoms suggestive of esophageal disorders. Scand J Gastroenterol 1991;26:73-81.

9 Locke GR, Talley NJ, Fett SL, et al. Prevalence and clinical spectrum of gastroesophageal reflux: a population-based study in Olmsted County, Minnesota. Gastroenterology 1997:112:1448-56.

10 Hollnagel $\mathbf{H}$, Nørrelund N, Larsen S. Mave-tarmsymptomer blandt 40-årige i Glostrup. En epidemiologisk undersøgelse (Gastrointestinal symptoms among 40-year olds in Glostrup. An epidemiological study) Ugeskr Laeger 1982;144:267-73.

11 Johnsen R, Straume B, Førde OH. Peptic ulcer and non-ulcer dyspepsia-a disease and a disorder. Scand J Prim Health Care 1988;6:239-43

12 Agréus L, Svärdsudd K, Nyrén O, et al. Irritable bowel syndrome and dyspepsia in the general population: overlap and lack of stability over time. Gastroenterology 1995;109:671-80.

13 Heading RC. Definitions of dyspepsia. Scand J Gastroenterol 1991;26(suppl 182):1-6.

14 Colin-Jones D, Bloom B, Bodemar G, et al. Management of dyspepsia: report of a working party. Lancet 1988;1:576-9.

15 Talley NJ, Colin-Jones D, Koch KJ, et al. Functional dyspepsia: a classification with guidelines for diagnoses and management. Gastroenterol Int 1991;4:145-60

16 Kaul B, Halvorsen T, Petersen H, et al. Gastroesophageal reflux disease. Scintigraphic, endoscopic, and histologic considerations. Scand J Gastroenterol 1986;21:134-8.

17 Johnston BT, Collins JS, McFarland RJ, et al. Are esophageal symptom reflux-related? A study of different scoring systems in a cohort of patients with heartburn. Am J Gastroenterol 1994;89:497-502.

18 Kingham JG, Fairclough PD, Dawson AM. What is indigestion? J R Soc Med 1983;76:183-6.
19 Helman C. Culture, health and illness. Bristol: Wright, 1984

20 Talley NJ, Stanghellini V, Heading RC, et al. Functional gastroduodenal disorders. Gut 1999;45(suppl II):II37-42.

21 Agréus L, Talley NJ. Challenges in managing dyspepsia in general practice. BN 1997:315:1284-8.

22 Thompson WG, Heaton KW. Functional bowel disorders in apparently healthy people. Gastroenterology 1980;79:283-8.

23 Doll R, Jones FA. Occupational factors in the aetiology of gastric and duodenal ulcers with an estimate of their incidence in the general population. Medical Research Council, Special Report Series 276. London: His Majesty's Stationery Office, 1951.

24 Weir RD, Backett EM. Studies of the epidemiology of peptic ulcer in a rural community: prevalence and natural history of dyspepsia and peptic ulcer. Gut 1968;9:75-83

25 Johansson S. Den vuxna befolkningens hälsotillståndlåginkomst-utredningen:Magbesvär. In: The state of health in the adult population - the low income investigation (Abdominal discomfort). Stockholm: Allmänna Förlaget, 1970:97-106.

26 Banke L. Ulcussygdommens Epidemiologi. København: FADL's Förlag, 1975.

27 Tibblin G. Introduction to the epidemiology of dyspepsia. Scand J Gastroenterol 1985;20(suppl 109):29-33.

28 Tibblin G, Bengtsson C, Furunes B, et al. Symptoms by age and sex. The population studies of men and women in Gothenburg, Sweden. Scand J Prim Health Care 1990;8:9-17.

29 Barrós PV, Pamo OR. Molestias digestivas en la población adulta de Lima (Digestive disorders in the adult population of Lima). Rev Gastroenterol Peru 1989:9:131-8.

30 Jones R, Lydeard S. Prevalence of symptoms of dyspepsia in the community. BM 1989:298:30-2.

31 Bernersen B, Johnsen R, Straume B, et al. Towards a true prevalence of peptic ulcer: the Sørreisa gastrointestinal disorder study. Gut 1990:31:989-92.

32 Holcombe C, Omotara BA, Padonu MK, et al. The prevalence of symptoms of dyspepsia in northeastern Nigeria. A random community based survey. Trop Geogr Med 1991;43:209-14.

33 Ihezue $\mathbf{C H}$, Oluwole FS, Onuminya JE, et al. Dyspepsias among the highlanders of Nigeria: an epidemiological survey. Afr J Med Med Sci 1996;25:23-9.

34 Schlemper RJ, van der Werf SD, Vandenbroucke JP, et al. Peptic ulcer, non-ulcer dyspepsia and irritable bowel syndrome in the Netherlands and Japan. Scand J Gastroenterol 1993;28(suppl 200):33-41.

35 Hu W, Hui W, Lam C, et al. Anxiety and depression are co-factors determining health care utilisation in patients with dyspepsia: a Hong Kong population based study. Gastroenterology 1997;112(suppl):A153.

36 Holtmann G, Goebell H, Talley NJ. Dyspepsia in consulters and non-consulters: prevalence, health-care seeking behaviour and risk factors. Eur J Gastroenterol Hepatol 1994;6:917-24.

37 Cupella F, Alessio I, Intropido L, et al. Dyspepsia and Helicobacter pylori infection. A study of a population of workers. G Ital Med Lav $1991 ; 13: 81-4$

38 Bommelaer G, Rouch M, Dapoigny M, et al. Epidemiology of intestinal functional disorders in an apparently healthy population. Gastroentero Clin Biol 1986;10:7-12.

39 Welch GW, Pomare EW. Functional gastrointestinal symptoms in a Wellington community sample. N Z Med J 1990;103:418-20.

40 Räihä IJ, Impivaara O, Seppälä M, et al. Prevalence and characteristics of symptomatic gastroesophageal reflux disease in the elderly. J Am Geriatr Soc 1992;40:1209-11.

41 Kay L, Jørgensen T. Epidemiology of upper dyspepsia in a random population. Prevalence, incidence, natural history and risk factors. Scand J Gastroenterol 1994;29:1-7.

42 Jones R, Lydeard S. Dyspepsia in the community: a follow-up study. Br J Clin Pract 1992;46:95-7.

43 Talley NJ, Weaver AL, Zinsmeister AR, et al. Onset and disappearance of gastrointestinal symptoms and functional gastrointestinal disorders. Am J Epidemiol 1992;15:165-77.

44 Lööf L, Götell P, Elfberg B. The incidence of reflux oesophagitis. A study of endoscopy reports from a defined catchment area in Sweden. Scand Gastroenterol 1993;28:113-18.

45 Dotevall G, Svedlund J, Siödin I. Symptoms in irritable bowel syndrome. Scand J Gastroenterol 1982;17(suppl 79): 16-19.

46 Jones R, Lydeard S. Irritable bowel syndrome in the general population. BM 1992;304:87-90.

47 Talley NJ, Piper DW. The association between non-ulcer dyspepsia and other gastrointestinal disorders. Scand J Gastroenterol 1985;20:896-900

48 Sielaff F. Coincidence between chronic dyspepsia and irritable bowel syndrome. Eur J Gastroenterol Hepatol 1990;2:S105-6.

49 Johannessen T, Petersen H, Kristensen $\mathrm{P}$, et al. The intensity and variability of symptoms in dyspepsia. Scand J Prim Health Care 1993;11:50-5.

50 Kay L, Jørgensen T. Upper dyspepsia among 30 to 60 year-olds -5 yea follow-up in a population study. Ugeskr Laeger 1995;157:2574-8.

51 Locke GL, Talley NJ, Zinsmeister AR, et al. Evidence that the irritable bowel syndrome and functional dyspepsia are single disorders: a population based study. Gastroenterology 1996;110(suppl):A26.

52 Agréus L, Svärdsudd K, Talley NJ, et al. Natural history of gastroesophageal reflux disease and functional abdominal disorders: a population-based study. Am J Gastroenterol 2001:96:2905-14.

53 Palmer ED. The hiatus hernia-esophagitis-esophageal stricture complex. Twenty-year prospective study. Am J Med 1968;44:566-79. 
54 Schindlbeck NE, Klauser AG, Berghammer G, et al. Three year follow up of patients with gastrooesophageal reflux disease. Gut 1992;33:1016-19.

55 Ruth $M$. Vad händer med esofagala symptom med tiden? (What happens with oesophageal symptoms over time?) Svenska Läkarsällsk Handl 1997; 106:GA42.

56 Agréus L. The abdominal symptom study. An epidemiological survey of gastrointestinal and other abdominal symptoms in the adult population of Osthammar, Sweden. In: Acta Universitatis Upsaliensis, Comprehensive summaries of Uppsala dissertations from the Faculty of Medicine, 434. Uppsala: Uppsala University, 1993.

57 Elta GH, Behler EM, Colturi TJ. Comparison of coffee intake and coffee-induced symptoms in patients with duodenal ulcer, nonulce dyspepsia, and normal controls. Am J Gastroenterol 1990;85:1339-42.

58 Talley NJ, McNeil D, Piper DW. Environmental factors and chronic unexplained dyspepsia. Association with acetaminophen but not other analgesics, alcohol, coffee, tea, or smoking. Dig Dis Sci 1988;33:641-8.

59 Talley NJ, Zinsmeister AR, Schleck CD, et al. Smoking, alcohol, and analgesics in dyspepsia and among dyspepsia subgroups: lack of an association in a community. Gut 1994;35:619-24.

60 Talley NJ, Fung LH, Gilligan I, et al. Association of anxiety, neuroticism, and depression with dyspepsia of unknown cause. A case-control study. Gastroenterology 1986;90:886-92

61 Kane F Jr, Strohlein J, Harper RG. Nonulcer dyspepsia associated with psychiatric disorder. South Med J 1993;86:641-6.
62 Langeluddecke P, Goulston K, Tennant C. Psychological factors in dyspepsia of unknown cause: a comparison with peptic ulcer disease. J Psychosom Res 1990;34:215-22.

63 Wiklund I, Butler-Wheelhouse P. Psychosocial factors and their role in symptomatic gastroesophageal reflux disease and functional dyspepsia. Scand J Gastroenterol 1996;31 (suppl 220):94-100.

64 Lydeard S, Jones R. Factors affecting the decision to consult with dyspepsia: comparison of consulters and non-consulters. J R Coll Gen Pract 1989;39:495-8.

65 Agréus L. Socio-economic factors, health care consumption and rating of abdominal symptom severity. A report from the Abdominal Symptom Study. Fam Pract 1993; 10:152-63.

66 Drossman DA, McKee DC, Sandler RS, et al. Psychosocial factors in the irritable bowel syndrome. A multivariate study of patients and nonpatients with irritable bowel syndrome. Gastroenterology 1988;95:701-8.

67 National Corporation of Swedish Pharmacies. Leveranser av varor från producenter/droghandel in till apoteken (Delivery of drugs to the pharmacies 1991-97). Stockholm: Statestikenheten, Riksförsäkringsverket, 1990, 1998.

68 Nyrén O, Lindberg G, Lindström E, et al. Economic costs of functional dyspepsia. Pharmacoeconomics 1992;1:312-24.

69 Levin TR, Schmittdiel JA, Kunz K, et al. Costs of acid-related disorders to a health maintenance organization. Am J Med 1997;103:520-8. 